\title{
A influência das mídias sociais no processo de decisão de compra: uma revisão integrativa
}

O marketing digital é uma das áreas mais amplas da administração, e também uma das áreas que mais permite o estudo e amplificação dos conhecimentos. As mídias sociais são hoje uma das principais fontes de informação e compartilhamento de dados, e é através dessas mídias que as empresas se comunicam com seus potenciais clientes. Este trabalho teve como objetivo prover aporte para profissionais e estudantes da área de administração para a compreensão da importância e aplicação do marketing digital através das mídias sociais como forma de influência no processo de decisão de compra. Este objetivo foi alcançado mediante levantamento bibliográfico, e análise crítica de estudos previamente publicados sobre o mesmo tema. Por intermédio deste estudo, pôde-se perceber as diferentes maneiras de influência que as mídias sociais exercem sobre o processo de decisão de compra.

Palavras-chave: Marketing Digital; Redes Sociais; Decisão de Compra.

\section{The influence of social media on the purchase decision process: an integrative review}

Digital marketing is one of the broadest areas of administration, and one of the areas that most enables the study and amplification of knowledge. Social media is today one of the main sources of information and data sharing, and it is through these networks that companies communicate with their potential customers. This study aimed to provide support to professionals and students in the administration area to understand the importance and application of digital marketing through social media as a way of influencing the purchase decision process. This objective was achieved by bibliographic survey and critical analysis of previously published studies on the same theme. Through this study it was possible to notice the different ways of influence that social network exert on the purchase decision process.

Keywords: Digital Marketing; Social Network; Purchasing Decision.

Topic: Marketing e Estratégias Mercadológicas

Reviewed anonymously in the process of blind peer.
Received: 10/01/2019

Approved: 13/04/2019
Sabrina Bezerra e Silva (i)

Centro Universitário Vale do Salgado, Brasil

http://lattes.cnpq.br/0286853211314989

http://orcid.org/0000-0001-6474-8251

sabrinabez@outlook.com.br

João José Anselmo dos Santos (iD

Centro Universitário Vale do Salgado, Brasil

http://lattes.cnpq.br/3210969164998188 anselmo@fvs.edu.br
Referencing this:

SILVA, S. B.; SANTOS, J. J. A.. A influência das mídias sociais no processo de decisão de compra: uma revisão integrativa. Entrepreneurship, v.4, n.1, p.8-16, 2020. DOI: http://doi.org/10.6008/CBPC2595-4318.2020.001.0002 


\section{INTRODUÇÃO}

Com o passar dos anos a internet se tornou o principal meio de compartilhamento de informações e opiniões, e nesse ambiente as pessoas podem comentar livremente sobre quaisquer assuntos que lhes sejam interessantes. Essa facilidade no fluxo de dados e informações permite que empresas possam desenvolver estratégias, usando dessa abertura, para atingir o maior número de pessoas possível, conquistando uma grande quantidade de leads.

Tais práticas são referentes ao desenvolvimento e aplicação do marketing digital, que é, ainda que tal conceito possa ser subjetivo, a promoção de produtos ou serviços, através de mídias digitais; as mídias sociais mudaram a maneira como as empresas se comunicam com os clientes, tirando do primeiro plano os meios de comunicação mais tradicionais, como TV, rádio e jornais, substituindo-os pelas redes sociais, como Facebook, Instagram ou Twitter; mudou-se também a forma como o cliente age no processo de decisão de compra, ora em suas buscas por melhores opções, ora atentando às opiniões de pessoas que adquiriram o mesmo produto ou serviço, dentre outros aspectos.

A forma pela qual o indivíduo é influenciado, seja, positiva ou negativamente, pelo marketing digital é de suma importância para que sejam desenvolvidas as melhores estratégias de marketing, de maneira ética, concisa e de forma a reduzir ao máximo gastos desnecessários. A partir disto, esta pesquisa foi realizada partindo do seguinte questionamento: De que maneira as mídias sociais influenciam no processo de decisão de compra de seus usuários?. Por conseguinte, tendo como objetivo prover aporte para profissionais e estudantes da área de administração para a compreensão da importância e aplicação do marketing digital através das mídias sociais como forma de influência no processo de decisão de compra.

O modo como uma empresa se utiliza das mídias sociais para influenciar seus consumidores deve ser tratada com grande importância por parte dos estudiosos de administração, empreendedorismo e principalmente marketing, pois com o conhecimento necessário poderão atuar de maneira mais assertiva em seus projetos, à vista disso, este estudo se justifica pela importância em se compreender tal influência, bem como entender de que maneira ela é exercida por parte das empresas.

O presente artigo se divide em seis partes, a contar com a introdução. Sucedida por um referencial teórico que irá prover ao leitor o conhecimento básico sobre marketing e marketing digital, afim de que possa compreender o universo em que este estudo se insere; em seguida será apresentada a metodologia, descrevendo os passos tomados para a conclusão desde estudo, incluindo a classificação da pesquisa e a seleção de amostragem; a quinta etapa deste trabalho é a análise e discussão dos dados obtidos, e por fim, a conclusão do estudo.

\section{REVISÃO TEÓRICA}

\section{Marketing e Marketing digital}

Para que se compreenda facilmente como as empresas se direcionam ao público utilizando-se das redes sociais, antes, é necessário se entender o conceito de marketing digital, e como ele pode ser aplicado, 
e aí então, afunilar essas definições até chegar ao viés do marketing digital aplicado ás redes sociais. O marketing em si, para Kotler et al. (2003), é uma ação administrativa e social, através da qual tanto indivíduos quanto empresas conseguem aquilo que desejam, através da criação, oferta e troca de produtos e valores uns para os outros. E levando em conta essa definição pode-se aplicá-la facilmente ao marketing digital, no qual tanto empresas quanto clientes conseguem aquilo que querem, através da oferta e da procura - nesse caso no ambiente digital - e troca de valores ou produtos.

Em se tratando do marketing digital, o mesmo se difere do marketing comum visto que trata da comunicação direta e bidirecional, partindo tanto da marca para o cliente, quanto do cliente para a marca. De acordo com Vidigal (2003), inicialmente, o marketing se caracterizava como uma atividade massiva, unidirecional, na qual o consumidor participava apenas passivamente, e cabia a marca todo o trabalho de comunicar, sem permitir que o consumidor pudesse responder diretamente.

Um termo usado para identificar um dos aspectos dessa nova maneira de se trabalhar o marketing, é marketing de permissão, que segundo Las Casas (2009, citado por MARIN et al., 2018), promove maior probabilidade de que a compra seja concluída, visto que esse marketing é direcionado para as pessoas certas, através de conteúdos de qualidade relativos ao seguimento que a empresa segue. Este tipo de marketing pode ser chamado também de marketing de conteúdo ou inbound marketing, no qual a empresa fornece uma solução para um problema pesquisado pelo possível cliente.

O advento da internet trouxe inúmeras vantagens para as marcas no que diz respeito a maneiras de se posicionar perante os consumidores, porém com essa facilidade de comunicação também surgem outros desafios, visto que a competitividade aumenta, e o consumidor tem mais acesso à informação. Ainda que o ambiente mercadológico tenha se tornado bastante desafiador com o advento do marketing digital, para Costa et al. (2015), essas mudanças trouxeram também uma inúmera gama de possibilidades de atuação.

\section{O Marketing Digital aplicado às Mídias Sociais}

A internet traz uma gama de possibilidades para que as empresas possam se comunicar mais facilmente com seus clientes, e agregar possíveis clientes através das mídias digitais. Isso facilita e agiliza o repasse de informações acerca do posicionamento da empresa, bem como sobre seus produtos e serviços. Os primórdios das Redes Sociais datam de meados dos anos 1990, quando, segundo Oliveira (2011) logo após o surgimento da internet, começou a serem criados os primeiros sites de compartilhamento de opiniões, como ClassMates.com, AOL Instant Messenger, entre outros.

Uma das principais mudanças que a internet trouxe para o marketing, segundo Kotler (2001), é o fato de que o ambiente online e essa 'revolução da informação' fazem com que seja alterado o destino dos participantes no processo de disponibilização de valor. Ou seja, muda-se o posicionamento do consumidor em relação a marca, podendo ele se tornar mais exigente, devido à grande facilidade de informações das quais dispõe; e muda também a forma como a marca se comunica com o público, sendo mais atenta a seus posicionamentos perante os assuntos discutidos em sociedade.

Partindo de um ponto exclusivamente do consumidor, existem diversos benefícios em se ter uma 
maior facilidade de acesso a marcas online; segundo Bayo-Moriones et al. (2007), tais benefícios podem ser eficiência, informação mais participativa, preço competitivo e uma maior gama de produtos podem ser obtidos devido a revolução do marketing digital; a medida que o consumidor tem mais informações e mais opções na ponta dos dedos, as empresas automaticamente devem se atualizar para oferecer o diferencial, causando assim a maior competitividade.

Para Silva (2016), as empresas devem tentar se aproximar dos consumidores e leads afim de fidelizar o cliente, e a partir disso receber comentários positivos e recomendações, que em grande parte são veiculadas nas redes sociais. Ou seja, uma participação ativa e bem elaborada nas redes sociais pode promover um vínculo mais aproximado empresa-cliente, reduzindo bastante o número de compradores casuais, e aumentando o número de clientes fidelizados.

Reiterando a importância de clientes que defenda a marca nas redes, para Evans et al. (2010), a melhor forma de engajar nas redes sociais é buscando colaboração orgânica e espontânea ou entusiástica de clientes satisfeitos; para o autor a base de qualquer estratégia de marketing digital de sucesso é através de comentários benéficos feitos por pessoas que adquiriram o produto ou serviço.

\section{METODOLOGIA}

O presente trabalho foi elaborado através de uma revisão integrativa de literatura, também chamada de revisão bibliográfica, um método que se resume em um estudo, análise e comparação de trabalhos já publicados anteriormente, a fim de se obter novos conhecimentos sobre um tema pré-definido (MENDES et al., 2008). Este estudo apresenta uma abordagem de natureza básica, quantitativa, do tipo descritiva, cuja finalidade foi analisar, através de revisão de literatura, dados e informações sobre a influência do marketing digital no processo de decisão de compra.

O tipo de metodologia escolhido foi baseado na necessidade observada pelo objetivo da pesquisa, visto que, a pesquisa descritiva é usada quando se espera descrever as características de determinado fenômeno ou população, visando tornar o conhecimento sobre tal área ainda mais acessível, combinando as diversas visões acerca do assunto. Segundo Gil (2008), esse tipo de pesquisa pode se dar através de levantamento bibliográfico.

Quadro 1: Publicações disponíveis entre 2014 a 2019, de acordo com os critérios de inclusão e exclusão

\begin{tabular}{|l|l|l|}
\hline Bases de Dados & Ocorrência Parcial dos Descritores & Ocorrência Total dos Descritores \\
\hline SPELL & 34 & 1 \\
\hline Google Scholar & 17 & 12 \\
\hline Science.gov & 70 & 2 \\
\hline TOTAL & 121 & 15 \\
\hline
\end{tabular}

A obtenção de dados foi feita através de consulta de publicações e artigos na área de marketing digital, e sucedida por leitura crítica dos artigos selecionados. Como critérios de inclusão, foram utilizados artigos da área de administração encontrados nas bases de dados Scientific Periodicals Eletronic (SPELL), Google Scholar e Science.gov, nos idiomas português e inglês, publicados no período de 2014 a 2019, sob os seguintes descritores: 'Marketing Digital', 'Redes Sociais' e ‘Decisão de Compra'. E como critérios de exclusão 
se enquadraram artigos que não se caracterizaram como da área de Administração, e artigos em duplicidade. Os resultados da obtenção de dados estão apresentados no Quadro 1.

A busca nas bases de dados acima citadas, e de acordo com os critérios de inclusão e exclusão, apresentou 1 publicação na Base de Dados SPELL, 9 publicações no Google Scholar, e 2 publicações na base de dados Science.gov, totalizando 15 artigos pré-selecionados. Através da busca filtrada nas bases de dados, foram levantadas 121 publicações, das quais foram descartadas aquelas em duplicidade, que não estivessem nos idiomas português ou inglês, ou que não possuíssem todos descritores em seu corpo de texto; e por conseguinte, através da leitura do título e do resumo, os quinze artigos foram congruentes com os critérios deste estudo, passando então para a etapa de leitura integral, na qual 5 artigos foram descartados; configurando ao fim da seleção, um total de 10 artigos adequados ao proposto por este estudo. A representação gráfica sobre a seleção dos artigos pode ser verificada na Figura 1.

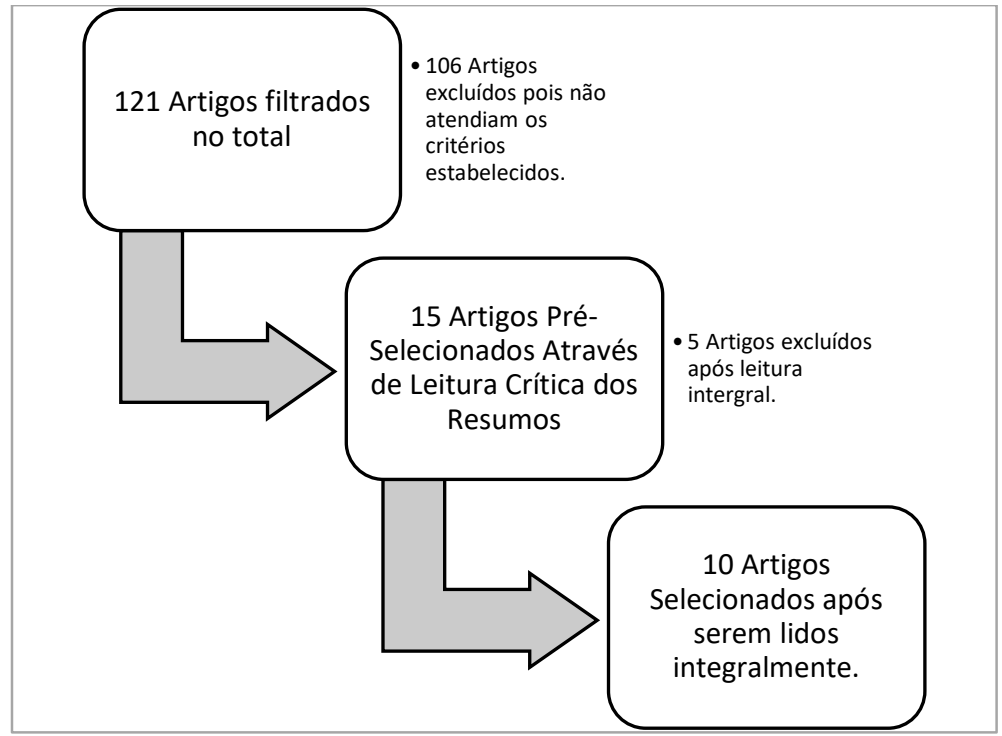

Figura 1: Representação Gráfica da Seleção de Amostra.

É válido esclarecer que ao serem lidos e analisados os quinze artigos pré-selecionados, quatro deles não se enquadravam no propósito deste estudo, visto que mesmo pertencendo à área de administração não condiziam com o tema abordado, e em vista disso, foram descartados. A análise dos dados obtidos foi feita através de leitura crítica dos estudos selecionados, sendo utilizados gráficos e quadros de acordo com sua conveniência. Todos os artigos e estudos citados nesta pesquisa serão devidamente referenciados conforme as normas da Associação Brasileira de Normas Técnicas (ABNT).

\section{RESULTADOS E DISCUSSÃO}

Os resultados deste estudo serão apresentados abaixo por meio de figuras, gráficos e tabelas, e através da exposição combinada dos dados encontrados nos artigos que compuseram a amostra. A seguir, no Quadro 2, encontram-se organizados por ordem de publicação, os títulos dos artigos que servem como amostra para este estudo. 
Quadro 2: Títulos e Autores dos artigos selecionados, classificados por ano de publicação

\begin{tabular}{|l|l|l|}
\hline Ano & Título do Artigo & Autores do Artigo \\
\hline 2014 & Associação entre intensidade de uso de mídias sociais, credibilidade e decisão de compra. & $\begin{array}{l}\text { MACLENNAN, M. L. } \\
\text { F. et al. }\end{array}$ \\
\hline 2016 & $\begin{array}{l}\text { A influência das mídias sociais no processo de compra: Análise do perfil do consumidor } \\
\text { universitário do Curso de Administração da Universidade Federal do Maranhão }\end{array}$ & SILVA, J. M. \\
\hline 2016 & The implopment of the Digital Marketing Strategy Based on Global Best Practices. & MALIK, S. \\
\hline 2017 & $\begin{array}{l}\text { A influência das mídias digitais no processo de decisão de Compra: um estudo de caso com } \\
\text { estudantes da graduação de administração da UFRN. }\end{array}$ & DAMASCENO, M. R. \\
\hline 2018 & $\begin{array}{l}\text { A influência das mídias sociais no processo de decisão de compra de produtos no varejo } \\
\text { farmacêutico. }\end{array}$ & MEDEIROS, F. A. M. \\
\hline 2018 & $\begin{array}{l}\text { O marketing digital sob a perspectiva das mídias sociais como fonte de informação para decisão } \\
\text { de compra no varejo de moda feminina }\end{array}$ & SOUZA, P. B. M. \\
\hline 2018 & $\begin{array}{l}\text { Influenciadores digitais e o seu poder de influência no processo de decisão de compra e na } \\
\text { construção da lealdade }\end{array}$ & VALENTE, J. C. S. \\
\hline 2019 & Factors affecting Social Media adoption among Wood Products Consumers in the United States & GAZAL, K. A. et al \\
\hline 2019 & $\begin{array}{l}\text { O efeito de micro digital influencers no comportamento de compra no Instagram em contextos } \\
\text { de produtos de moda }\end{array}$ & BASSO, L. C. \\
\hline
\end{tabular}

\section{Especificações da Amostra}

A amostra para este estudo foi caracterizada através de seu método de estudo e idioma de publicação. No Gráfico 1, é possível analisar a distribuição dos trabalhos selecionados de acordo com o idioma de publicação.

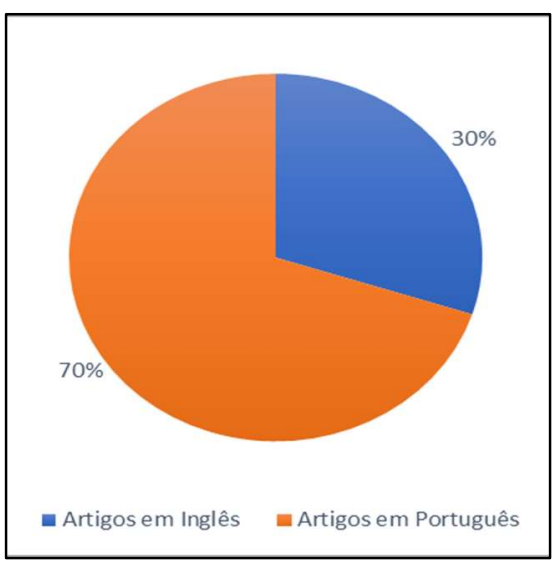

Gráfico 1: Classificação da Amostra quanto ao idioma de publicação.

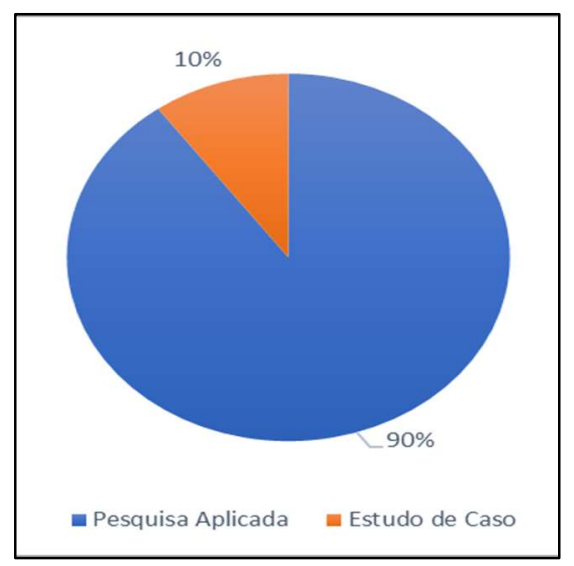

Gráfico 2: Classificação dos Artigos selecionados quanto ao tipo de pesquisa.

Dos artigos selecionados para amostra, três (30\%) foram publicados em inglês, e sete $(70 \%)$ foram publicados em português. A base de dados Google Scholar foi a única a disponibilizar artigos nos dois idiomas; enquanto a SPELL apresentou apenas artigos em português, e a base de dados Science.gov, mostrou apenas artigos em inglês. Pôde-se perceber, então, que ao utilizar os descritores selecionados, os estudos no idioma português superam em quantidade os estudos em inglês, podendo sugerir que estudiosos de países de língua portuguesa tenham mais afinidade ou inclinação à pesquisa no que se refere à influência das redes sociais no comportamento de compra dos usuários.

Sobre a metodologia utilizada nos trabalhos analisados, é possível perceber, através do Gráfico 2 que 90\% dos estudos, o que correspondem a nove dos dez trabalhos utilizados, foram feitos através de pesquisa aplicada, seja por meio de pesquisa de campo, ou, como em um dos trabalhos, focus group, e em outros surveys e entrevistas. E apenas $10 \%$, referentes a um dos dez trabalhos selecionados, correspondem a 
pesquisa baseada em revisão de literatura em combinado a um estudo de caso.

\section{Caracterização da Influência das Mídias Sociais no Processo de Decisão de Compra}

Caracterizar a visão geral dos estudos selecionados para amostra é o principal meio de se entender de maneira geral a influência que o marketing digital exerce sobre o processo de decisão de compra dos usuários das mídias sociais. De acordo com os dados obtidos, a percepção dos autores em relação a maneira como ocorre a influência no comportamento do consumidor pode ser dividida em quatro grupos de opiniões centrais: 'Forte Influência', no qual os autores afirmam a hegemonia das redes sociais no marketing, citando a utilização de influenciadores digitais para promoção de marcas ou produtos (BASSO, 2019); 'Atuação da Empresa', que enfatiza o planejamento das em presas em relação a suas campanhas de marketing online como principal influenciador do processo de decisão de compra; 'Marca x Consumidor', afirmando que grande parte da influência produzida pelas mídias sociais no processo decisivo da compra ocorre por meio da facilidade de interação entre empresa e consumidor; e por fim o grupo 'Comentários', que trata da influência causada através dos comentários e opiniões de outros usuários de redes sociais, acerca de determinado produto ou serviço. Por conseguinte, o Quadro 3, apresentado a seguir, exibe uma síntese das definições de tal influência, segundo os autores selecionados para este estudo.

Quadro 3: Panorama acerca da percepção dos autores sobre a influência das mídias digitais no processo de decisão de compra.

\begin{tabular}{|l|l|l|}
\hline \multicolumn{1}{|c|}{ Panorama } & \multicolumn{1}{|c|}{ Autores } & \multicolumn{1}{c|}{ Citação Indireta } \\
\hline Forte Influência. & $\begin{array}{l}\text { (SILVA, J. M., 2016; MEDEIROS, G. F. A, } \\
\text { 2018; BASSO, L. C., 2019; SOUZA, P. B. } \\
\text { M, 2018.; BOM, I. S. I., 2016) }\end{array}$ & $\begin{array}{l}\text { O marketing digital está presente em todos os âmbitos da } \\
\text { internet, logo, se faz inegável sua forte influência no } \\
\text { comportamento do consumidor, inclusive com o auxílio de } \\
\text { 'Digital Influencers'. }\end{array}$ \\
\hline $\begin{array}{l}\text { Forte atuação das } \\
\text { Empresas. }\end{array}$ & (MALIK, S., 2016; BOM, I. S. I., 2016) & $\begin{array}{l}\text { Há por parte das empresas uma forte preocupação e } \\
\text { planejamento sobre como as informações serão transmitidas } \\
\text { ao público. }\end{array}$ \\
\hline $\begin{array}{l}\text { Proximidade entre } \\
\text { marca e consumidor. }\end{array}$ & $\begin{array}{l}\text { (GAZAL, A. G.; MONTAGUE, I. B.; } \\
\text { WIENDENBECK, J. K., 2019; VALENTE, J. J., 2018, DAMASCENO, M. R., 2017) }\end{array}$ & $\begin{array}{l}\text { A interação entre consumidores e comerciantes está } \\
\text { crescendo em importância, com o rápido aumento no uso de } \\
\text { redes sociais, e de sua popularidade. }\end{array}$ \\
\hline $\begin{array}{l}\text { Importância de } \\
\text { comentários de } \\
\text { outros usuários. }\end{array}$ & $\begin{array}{l}\text { (MACLENNAN, M. L. F et al., 2014; } \\
\text { DAMASCENO, M. R., 2017) }\end{array}$ & $\begin{array}{l}\text { Deve-se considerar que comentários de outros usuários de } \\
\text { mídias sociais acerca de determinada marca ou produto } \\
\text { influenciam seu nível de credibilidade. }\end{array}$ \\
\hline
\end{tabular}

A seguir é apresentado o Gráfico 3, o qual exibe a ocorrência de autores em cada um dos grupos citados. Como pode ser percebido por meio do gráfico 3, as ocorrências de artigos no grupo 'Forte Influência' correspondem a $41 \%$ do total de ocorrências, representando cinco artigos que fazem parte deste grupo; já o número de artigos na categoria 'Marca x Consumidor', corresponde a 25\% do total de ocorrências, totalizando três artigos neste grupo; as ocorrências nos grupos 'Atuação da Empresa' e 'Comentários', contam cada uma como $17 \%$ de participação nas ocorrências de suas respectivas categorias, cada uma com dois artigos sendo englobados neste grupo. Vale ressaltar que dois dos dez artigos tomados como amostra, se enquadrou em mais de uma categoria, pois enfatizavam mais de uma visão sobre a influência das mídias sociais no processo de decisão de compra. 


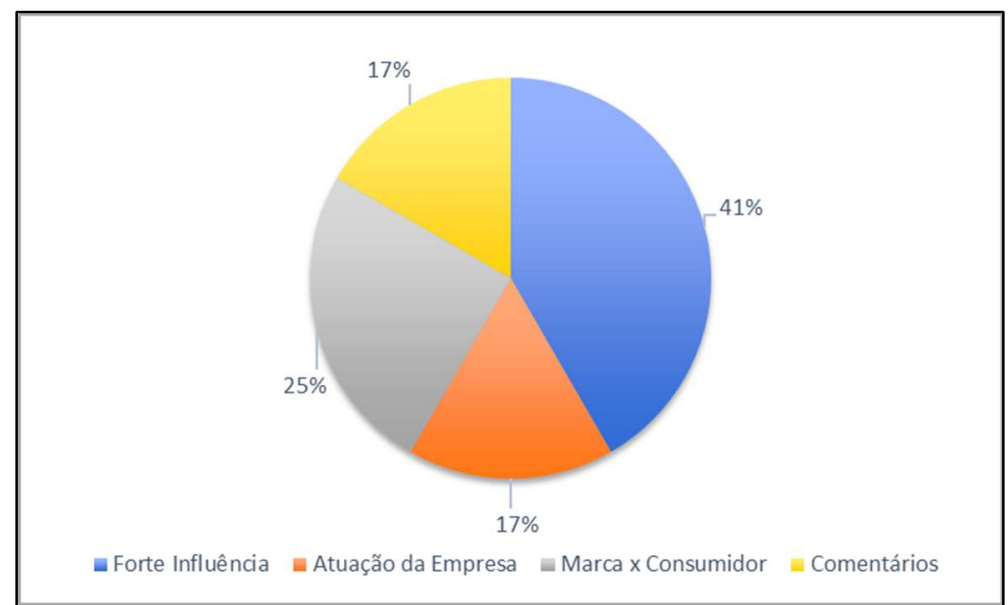

Gráfico 3: Ocorrência de artigos em cada grupo de opiniões.

As informações contidas nos artigos nos mostram que há diversas maneiras pelas quais pode ocorrer a influência no processo decisório de compra, através das mídias sociais, mas que em grande parte, essa influência se dá pelo contato direto do consumidor com as ações de marketing digital das empresas, bem como pelo contato com os chamados 'digital influencers'; entretanto, a relação e comunicação direta da marca com o possível consumidor também é significativamente importante no processo de decisão de compra, visto que por ter uma maior abertura nos canais de comunicação com a empresa, o consumidor pode se sentir mais seguro ao efetuar a compra; essa segurança também pode ser obtida através do contato com comentários de outras pessoas que já tiveram acesso a determinado produto ou serviço que ocasionalmente seja do interesse do possível consumidor. Vale destacar a relevância da atuação da empresa por si só, seja em seu planejamento de marketing, ou até mesmo na criatividade em suas campanhas, visto que é isso quem chama a atenção do provável consumidor num primeiro momento.

\section{CONCLUSÕES}

O presente estudo teve como objetivo promover maior conhecimento na área do marketing digital, em específico sobre as mídias digitais e seu poder de influência no processo de decisão de compra, através da seguinte pergunta norteadora: De que maneira as mídias sociais influenciam no processo de decisão de compra de seus usuários? Após seleção, leitura crítica e análise de outros estudos da área, a provável resposta para esta pergunta pode ser encontrada na análise dos resultados da pesquisa, onde foram expostas, de maneira detalhada, as diversas informações e opiniões acerca dessa influência.

Os resultados deste estudo foram baseados no estudo de dez artigos, devidamente selecionados, publicados entre os anos de 2014 e 2019 e apresentados através de gráficos e tabelas, por meio dos quais se pode perceber que é inegável a influência das mídias digitais no processo de decisão de compra, seja através de influenciadores digitais, contato direto com as empresas, ou até mesmo contato com outros usuários das mídias sociais.

Recomenda-se que os estudantes de administração e marketing compreendam de fato como funciona o marketing digital, e a influência exercida pelo mesmo no comportamento dos consumidores, visto que as mídias sociais estão se tornando, se não já são, a principal fonte de obtenção e troca de informações, 
ou seja, é nas redes sociais que se encontram os compradores em potencial.

Uma maneira de se adquirir este conhecimento é por meio de levantamento bibliográfico, utilizandose das mais diversas bases de dados, e conectando e comparando informações apresentadas por diferentes autores, em diferentes localidades, ampliando ainda mais a gama de artigos e estudos sobre este tema tão relevante dentro da administração.

\section{REFERÊNCIAS}

BASSO, L. C.. O efeito de Micro Digital Influencers no comportamento de compra no Instagram em contextos de produtos de moda. Monografia (Graduação em Administração) - Universidade de Caxias do Sul, Caxias do Sul, 2019

BAYO-MORIONES, A.; LERA-LÓPEZ, F.. A firm-level analysis of determinants of ICT adoption in Spain. Technovation, v.27, n.6-7, p.352-366, 2007.

BOM, I. S. I.. The impact of YouTube recommendations on consumer's decision-making process. Dissertação (Mestrado) - Instituto Universitário de Lisboa, Lisboa, 2016.

COSTA, L. M.; DIAS, M. M. S.; SANTOS, E. A.; ISHII, A. K. S.; AS, J. A. S.. A Evolução do Marketing Digital: uma estratégia de mercado. Tese (Doutorado em Engenharia de Produção) Universidade do Estado do Pará, Fortaleza, 2015.

DAMASCENO, M. R.. A Influência das Mídias Digitais no Processo de Decisão de Compra: Um Estudo de Caso com Estudantes da Graduação de Administração da UFRN. Monografia (Graduação em Administração) - Universidade Federal do Rio Grande do Norte, Natal, 2017.

EVANS, D.; MCKEE, J.. Social Media Marketing: The Next Generation so Business Engagement. Indianapolis: Wiley Publishing Inc., 2010.

GAZAL, K. A.; MONTAGUE, I. B.; WIEDENBECK, J. K.. Factors Affecting Social Media Adoption among Wood Products Consumers in the United States. BioProducts Business, v.4, n.5, p.51-62, 2019.

GIL, A. C.. Como elaborar projetos de pesquisa. 4 ed. São Paulo: Atlas, 2008.

KOTLER, P.; ARMSTRONG, G.. Princípios de marketing. 9 ed. São Paulo: LTC, 2003.

KOTLER, P.. Marketing para o século XXI: como criar, conquistar e dominar mercados. 9 ed. São Paulo: Futura, 2001.

MALIK, S.. Development of the Digital Marketing Strategy Based on Global Best Practices. Tese (Mestrado em Gestão)
- Nova School of Business and Economics, Lisboa, 2016.

MARIN, A. C.; JUNGER, A. P.; MOSLAVACZ, F. L.; SOUZA, J. F.. Marketing digital como ferramenta de inovação e alavancagem de negócios. Research, Society and Development, v.7, n.3, p.1-13, e673150, 2018.

MACLENNAN, M. L. F.; LUGOBONI, L. F.; ZITTEI, M. V. M.; TABATA, R. Y.; CORRÊA, H. L.. Associação entre intensidade de uso de mídias sociais, credibilidade e decisão de compra. Revista de Gestão e Tecnologia, v.4, n.2, p.65-77, 2014.

MEDEIROS, G. F. A.. A Influência das mídias sociais no processo de decisão de compra de produtos no varejo farmacêutico. Monografia (Graduação em Administração) Universidade Federal do Rio Grande do Norte, Natal, 2018.

MENDES, K. D. S.; SILVEIRA, R. C. C. P.; GALVÃO, C. M.. Revisão integrativa: método de pesquisa para a incorporação de evidências na saúde e na enfermagem. Texto Contexto Enfermagem, Florianópolis, v.17, n.4, p.758764, 2008.

OLIVEIRA, N.. A história das Redes Sociais. 2011.

SILVA, J. M.. A influência das mídias sociais no processo de compra: Análise do perfil do consumidor universitário do Curso de Administração da Universidade Federal do Maranhão. Monografia (Graduação em Administração) Universidade Federal do Maranhão, São Luís, 2016.

SOUZA, P. B. M.. O marketing digital sob a perspectiva das mídias sociais como fonte de informação para decisão de compra no varejo de moda feminina. Dissertação (Mestrado em Administração) - Universidade FUMEC, Belo Horizonte, 2018.

VALENTE, J. C. S.. Influenciadores digitais e o seu poder de influência no processo de decisão de compra e na construção da lealdade. Dissertação (Mestrado em de Marketing e Negócios Internacionais) - Instituto Politécnico de Coimbra, Coimbra, 2018.

VIDIGAL, M. T.. E-Marketing: o marketing na internet, com casos brasileiros. São Paulo: Saraiva, 2003.

A CBPC - Companhia Brasileira de Produção Científica (CNPJ: 11.221.422/0001-03) detém os direitos materiais desta publicação. Os direitos referem-se à publicação do trabalho em qualquer parte do mundo, incluindo os direitos às renovações, expansões e disseminações da contribuição, bem como outros direitos subsidiários. Todos os trabalhos publicados eletronicamente poderão posteriormente ser publicados em coletâneas impressas sob coordenação da Sustenere Publishing, da Companhia Brasileira de Produção Científica e seus parceiros autorizados. Os (as) autores (as) preservam os direitos autorais, mas não têm permissão para a publicação da contribuição em outro meio, impresso ou digital, em português ou em tradução. 